\title{
Guest Editorial: Issue Two. Neoliberal Issues in Public Education
}

\author{
Carol A. Mullen • Fenwick W. English • \\ Sue Brindley $\cdot$ Lisa Ehrich $\cdot$ Eugenie A. Samier
}

Published online: 7 March 2013

(C) Springer Science+Business Media Dordrecht 2013

In this second issue of a two-volume set, we introduce four papers that continue the theme of neoliberal issues in public education articulated in the first issue. The 16 authors from issues one and two have written papers that describe as well as problematize neoliberal issues, influences, and networks. Focused but varied inquiry on pivotal issues in education are explored through rigorous approaches to empirical research and in-depth, "edgy" argumentation. The topics covered in the special issue across the two-part volume include the following and expand beyond this list:

- Intersections between democratic and neoliberal agendas, tensions between restricted-access networks and open-access networks, and communities of practice and regulatory bodies:

\section{A. Mullen ( $\bowtie)$}

Virginia Tech, 226 War Memorial Hall (0313), Blacksburg, VA 24061, USA

e-mail: camullen@vt.edu

F. W. English

3001 Staffield Lane, Chapel Hill, NC 27516, USA

e-mail: fenglish@attglobal.net

\section{S. Brindley}

Faculty of Education, University of Cambridge, 184 Hills Road, Cambridge CB2 8PQ, UK e-mail:sb295@cam.ac.uk

\section{Ehrich}

School of Learning \& Professional Studies, Faculty of Education, Queensland University of Technology, A Block, Kelvin Grove Campus, Victoria Park Road, Brisban, QLD 4059, Australia e-mail: 1.ehrich@qut.edu.au

\section{E. A. Samier}

Faculty of Education, The British University in Dubai, 1st \& 2nd Floor, Block 11, Dubai International Academic City (DIAC), PO Box 345015, Dubai, United Arab Emirates e-mail: eugenie.samier@build.ac.ae 
- Analysis of the work between school districts and preparation programs as related to neoliberal agendas.

- Networked learning within national and international consortia of teacher and leadership preparation programs.

- Probing of networks within "policed" states and trends relating to privatization and the depoliticization of education.

- Discussion of hidden but emerging systems that influence the neoliberal agenda in a region or the world.

- Need for open and critical dialogue relative to neoliberal agendas (e.g., corporate marketing schemes).

In the articles that follow, the authors who are currently working in universities in the United Kingdom and the United States, describe neoliberalism in ways that are engaging, provocative, and even somewhat arresting. The focus on neoliberalism (e.g., influences and networks) gives attention to such broad areas as public education, Barack Obama's presidency, whiteness, racism, school networks, teacher professionalism, social movements, preservice teachers, decolonization, multicultural awareness, international field experience, and study abroad. Key concepts explored collectively by the group of authors from both issues is revealing of the associations we have with neoliberalism, as well as our critiques and alternatives (e.g., faculty voice and democratic decision making). Grouped together without positive or negative values of neoliberalism labelled in this broad swipe, major concepts the contributors describe are neoliberalism (e.g., neoliberal networks, agenda, culture, politics), globalization, Regressionsverbot, epistemic frame, leadership listening, faculty voice, democratic decision making, college faculty governance, corporatization of the university, popular culture, social capital, social reproduction, social Darwinism, education austerity, democratic public school, and unitary school system. The authors use critical social and educational theories to explore and problematize, as well as interrogate, neoliberalism in its varied forms. We turn now to briefly describe each of the articles in this second issue of the two-volume set.

First, Thomas Hairston of the University of Missouri in "Continuing inequity through neoliberalism: the conveyance of white dominance in the educational policy speeches of President Barack Obama" engages in critical discourse analysis to examine how President Barack Obama's political statements play a role in perpetuating practices and policies of White privilege by constructing education in a neoliberal frame. This research serves to propel educational discussions of the influence of whiteness and racism on public education and of the important role of leadership in countering racism with their constituents.

Second, in "Turnaround as reform: opportunity for meaningful change or neoliberal posturing?" Ian Mette of the University of Missouri explores the neoliberal agenda of turnaround school reform efforts in America by examining the application and transformation of a midwest state turnaround school in a state's public schools. Perceptions of administrators and state-level policy actors are considered. Alarming findings point to how turnaround school policy implementation weakens control of democratically elected authorities and stagnates critical thinking that challenges the interests behind turnaround school policy. 
Next, from the University of Nottingham Andrew Townsend charts the development of the neoliberal education market and explores ways in which three case study networks, all members of the networked learning communities programme, related to that context. In "Rethinking networks in education: case studies of organisational development networks in neoliberal contexts," the author identifies problems with and benefits of networking. Alternatives are proposed involving the reconsideration of education networks from the perspective of social movements associated with such values as a shared commitment to collaboration and identification with social movements. The idea here is to broaden the potential scope of changes resulting from networks and achieve those aspired aims.

The article "How preservice teachers engage in the process of (De)colonization: findings from an international field experience in Honduras" concludes this volume and special issue. Researchers Suniti Sharma (Saint Joseph's University), Jubin Rahatzad (Purdue University), and JoAnn Phillion (Purdue University) explore powerful neoliberal forces and produce the alternative of critical multicultural education, associated with the promise of cultural inclusion and such practices as open dialogue. Through critical dialogue, preservice teachers negotiate difference, engage with the self and other, and question their own knowledge and practices in sustaining colonial relations of privilege and domination. The authors advocate for the kind of multicultural awareness at every stage of teacher preparation for effecting change in classroom practice. The goal is for all students, including diverse minority populations, to experience educational equity and equal opportunities for academic success.

Readers, the four articles featured in the issue one of this special issue are as follows:

1. An epistemic frame analysis of neoliberal culture and politics in the US, UK, and the UAE by Carol A. Mullen, Eugenie A. Samier, Sue Brindley, Fenwick W. English, and Nora K. Carr.

2. Continuing inequity through neoliberalism: the conveyance of white dominance in the educational policy speeches of President Barack Obama by Thomas W. Hairston.

3. Exposing the effects of the "invisible hand" of the neoliberal agenda on institutionalized education and the process of sociocultural reproduction by John A. Cassell and Thomas Nelson.

4. Faculty Governance in neoliberal educational contexts: challenges for democratic decision making by Dilys Schoorman and Michele Acker-Hocevar.

With respect to acknowledgements, as guest editors we wish to express our appreciation to the contributors whom we are convinced have produced groundbreaking work that will hopefully serve to awaken institutions, policymakers, and the public. Moreover, we are grateful for the unwavering support and freedom we received from Editor Ian Winchester and editorial manager Denise Retzlaff and, formerly, Linda Lentz. Because of the latitude the Interchange editors gave us with this scholarly venture, we were all able to breathe into existence our ideas, concerns, and new possibilities. We would be remiss not to thank the reviewers who extended themselves all hours of the day and night on the global clock, providing detailed 
constructive critiques from which the articles most definitely benefitted. We are pleased to be contributing this special issue to a journal that has demonstrated its commitment to counter-hegemonic theories and arguments in the greater effort to imagine a better world and tomorrow.

As education scholar-practitioners, we seek to foster exchanges among practitioners, policymakers, and scholars and to provide a forum for comment on issues and trends in education. In the spirit of the journal, we have engaged in frank argumentative articles on the changing purposes of education. The articles challenge conventional assumptions about education and higher education and current trends in our institutional domains. Once again, we invite readers to respond, react, and shout out as they read our thoughts.

\section{Guest Editors and Contributions}

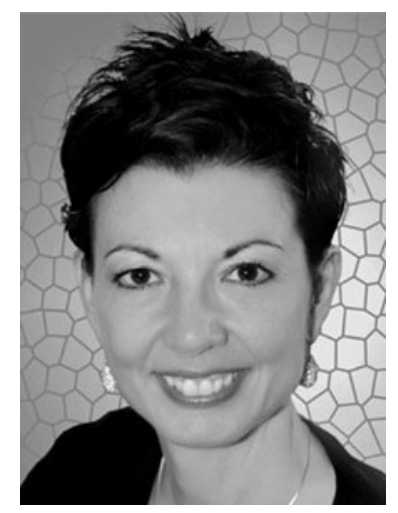

Carol A. Mullen, PhD, is a professor of educational leadership at Virginia Tech, Blacksburg, Virginia, USA, where she is the Director of the School of Education and Associate Dean for Professional Education of the College of Liberal Arts and Human Sciences. She was previously at The University of North Carolina at Greensboro where she served as chair of the Department of Educational Leadership and Cultural Studies, School of Education, for 5 years. Carol's research and teaching interests are mentoring theory and practice, diversity in educational contexts, and applied scholarly writing. Carol mentors graduate students and new professionals, collaborating with a wide variety of scholars and practitioners. From 2002 to 2010, she was the editor of the Mentoring \& Tutoring: Partnership in Learning journal (Routledge/Taylor \& Francis). Her authorships encompass more than 200 refereed journal articles and book chapters, 15 special issues of journals, and 17 books. Recent books include the coedited volume The SAGE Handbook of Mentoring and Coaching in Education (Sage, 2012); the coauthored book Educational Leadership at 2050: Conjectures, Challenges, and Promises (Rowman \& Littlefield Education, 2012), and, as single author, From Student to Professor: Translating a Graduate Degree into a Career in Academia (R\&L Education, 2012). 
Carol's governance work in the realm of administrative leadership, international relations, and human rights includes her recent role as the Kappa Delta Pi (KDP) Representative to the United Nations on behalf of the UN Department of Public Information, USA. From 2012 to 2013 she served as President of the National Council of Professors of Educational Administration and for 2 years as the University Council for Educational Administration Plenary Session Representative. Awards for scholarship include AERA's Award for Breaking the Circle of One, a university presidential award for faculty excellence, a women's leadership award, and several doctoral mentoring and teaching awards. She has founded and coordinated numerous mentoring and writing networks and programs for professional associations and universities. She earned her doctorate from The Ontario Institute for Studies in Education of the University of Toronto, Canada's most distinguished university. Email:camullen@vt.edu.

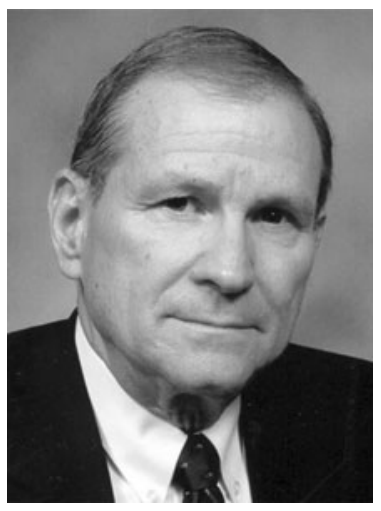

Fenwick W. English, PhD, is the R. Wendell Eaves Senior Distinguished Professor of Educational Leadership in the School of Education at the University of North Carolina at Chapel Hill. Formerly he served as a program coordinator, department chair, dean, and vice-chancellor of academic affairs at universities in Ohio and Indiana. As a K-12 practitioner, he has been a superintendent of schools in New York, an assistant superintendent of schools in Florida, and a middle school principal in California. He also had a stint as an associate executive director of the American Association of School Administrators and a partner in Peat, Marwick, Main \& Co. (now KPMG Peat Marwick) where he was national practice director for elementary and secondary education in Washington, D.C. Fenwick recently served as editor of The SAGE Handbook of Educational Leadership (2005) and the SAGE General Editor of the Encyclopedia of Educational Leadership and Administration (2006). His most recent books are The Art of Educational Leadership (2008) released by SAGE; Anatomy of Professional Practice (2008) released by Rowman 
\& Littlefield Education, and Educational Leadership at 2050 (2012) with Rosemary Papa, Carol A. Mullen, and Ted Creighton published jointly by NCPEA and Rowman \& Littlefield Education. He is past President of the University Council of Educational Administration (UCEA) and past President of National Council of Professors of Educational Administration (NCPEA). He served as an executive leader with UCEA for 7 years and President in 2006-2007. He is also past President of NCPEA. He is the 2012 NCPEA Living Legend. Email: fenglish@attglobal.net.

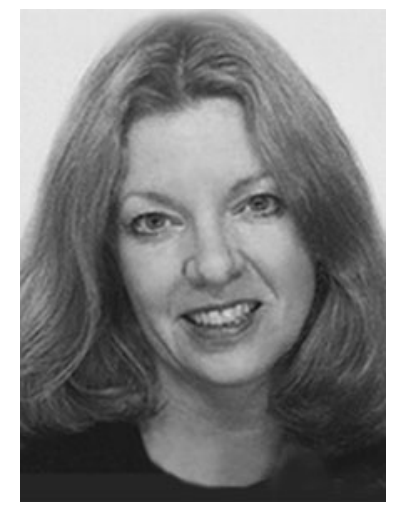

Sue Brindley $\mathrm{PhD}$, is a senior lecturer at the University of Cambridge, UK, where she developed and coordinates a blended learning Masters in Education (MEd), Researching Practice. She is general editor of a subject series on researching at the masters level, MasterClass (Bloomsbury). Her current interests are working with teachers and schools on professional development through practitioner research (CamStar: Cambridge, School Teachers and Research). She is particularly interested in the legitimisation of professional knowledge and the enhancement of professionalism through research. CamStar brings her into contact with substantial numbers of teachers working across a wide range of areas, and she is currently working on a networked school project (with 20 schools) on the question of what makes an outstanding school. A previous research emphasis on dialogic teaching led to a 2-year funded research project (Esmee Fairbairn) exploring dialogic teaching, learning, and assessment in secondary schools (CamTalk). Sue is also widely involved in researching digital technologies, teaching and learning with a particular interest on the extension, enhancement, and transformation potentials of digital technologies for classroom practitioners. Sue is general editor of two series on teaching with Digital Technologies (Open University Press and Bloomsbury). Sue is Editor of the journal of Teacher Development and serves on editorial boards for other journals. International work includes working with schools in Argentina in developing a teacher research based approach to assessment, and with Outreach India, a teacher exchange scheme based at the Faculty of Education. In 2012 Sue was 
awarded the prestigious Pilkington Prize from her university, recognizing excellence and innovation in her work. Email: sb295@cam.ac.uk.

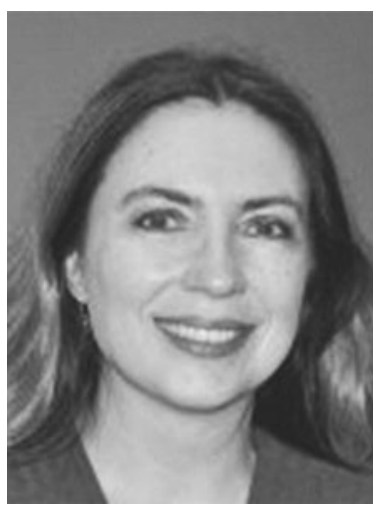

Lisa C. Ehrich, $\mathrm{PhD}$, is an associate professor of educational leadership in the School of Cultural and Professional Learning in the Faculty of Education at Queensland University of Technology (QUT). She has worked for more than 20 years in higher education and commenced her career as a secondary teacher. Over the last decade, she has taught primarily in post-graduate programs such as the Doctor of Education and Masters of Education program and, until recently, was the coordinator of the leadership and management areas of interest within the masters program. In addition to teaching domestic students, she has designed and delivered short professional development courses for teachers, school leaders, and university academics from countries such as China, Vietnam, Thailand, and the Philippines. Lisa's research interests include the principalship, mentoring for professionals, phenomenology, and grassroots leadership. She has published six books (two coauthored, four coedited), most recently Perspectives on Practical Experiences in Professional Education (2011, Post Pressed). She has published over 130 refereed papers including journal articles, books chapters, and conference papers. She is on the editorial board of a number of journals including Teacher Development, Leading \& Managing, and International Journal of Educational Management. In 2012, she and colleagues from QUT and the University of Manchester were awarded an Australian Research Council grant to explore ethical leadership in a time of evidence-based school reform. She completed her PhD from Queensland University of Technology, Australia. Email: 1.ehrich@qut.edu.au. 


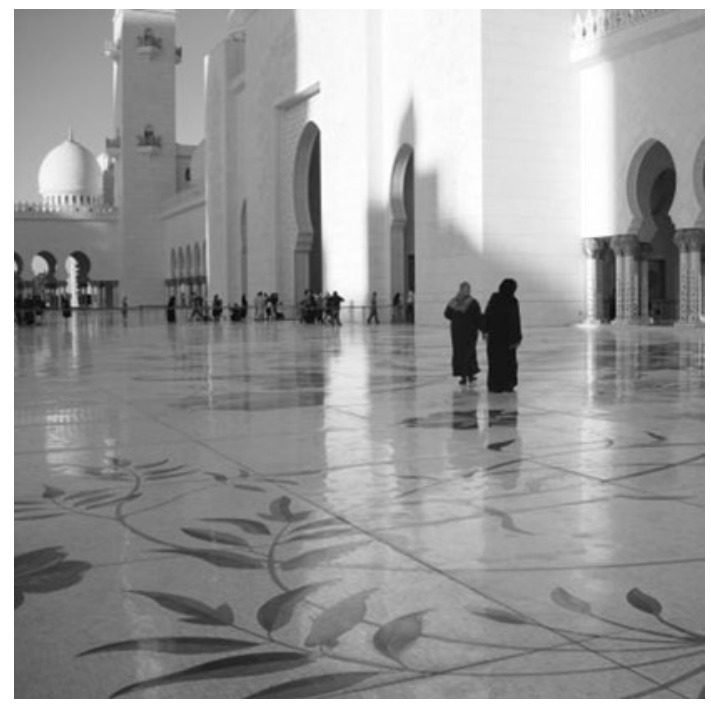

Eugenie A. Samier, $\mathrm{PhD}$, is an associate professor at The British University in Dubai, United Arab Emirates, Honourary Lecturer at the University of Birmingham, and a Visiting Fellow of Oxford Brookes University. She is author of articles on organisational culture, values and ethics, the New Public Management, history and biography, comparative management, and Weberian foundations appearing in a number of leading journals. She is editor and contributor to five titles with Routledge on ethics, aesthetics, politics, emotional dimensions, and trust and betrayal. She is currently working on literary representations and cinematic critiques, comparative leadership, and covert management and administration. She is one of four associate editors of the Educational Leadership and Administration (Sage, 2009) and a contributor to the Encyclopedia of Education Law (Sage, 2008), the new edition of the Handbook to Educational Leadership (Sage, 2011), and Handbook of Educational Theories (Information Age Publishing, forthcoming). Eugenie's most recent title Educational Administration, Secrecy and Tradecraft: The Covert Side of Educational Life (Routledge) is forthcoming. She has been guest lecturer at a number of universities in Germany, Estonia, Norway, Finland, the US, the UK, Russia, and Lithuania and serves on the editorial boards of the Halduskultuur journal, Teacher Development journal, and the Journal of Educational Administration and History. Email: eugenie.samier@buid.ac.ae. 